Portland State University

PDXScholar

$1-29-2016$

\title{
Cycling by Choice or Necessity? Exploring the Gender Gap in Bicycling in Oregon
}

Patrick Allen Singleton

Portland State University, singletonpa@gmail.com

Follow this and additional works at: https://pdxscholar.library.pdx.edu/trec_seminar

Part of the Transportation Commons, and the Urban Studies and Planning Commons Let us know how access to this document benefits you.

\section{Recommended Citation}

Singleton, Patrick Allen, "Cycling by Choice or Necessity? Exploring the Gender Gap in Bicycling in Oregon" (2016). TREC Friday Seminar Series. 86.

https://pdxscholar.library.pdx.edu/trec_seminar/86

This Book is brought to you for free and open access. It has been accepted for inclusion in TREC Friday Seminar Series by an authorized administrator of PDXScholar. Please contact us if we can make this document more accessible: pdxscholar@pdx.edu. 


\section{Cycling by choice or necessity? Exploring the gender gap in bicycling in Oregon}

\section{Patrick Singleton \& Tara Goddard Portland State University}

Friday Transportation Seminar Series

29 January 2016 | Portland, OR 


\section{Gender gap in bicycling}

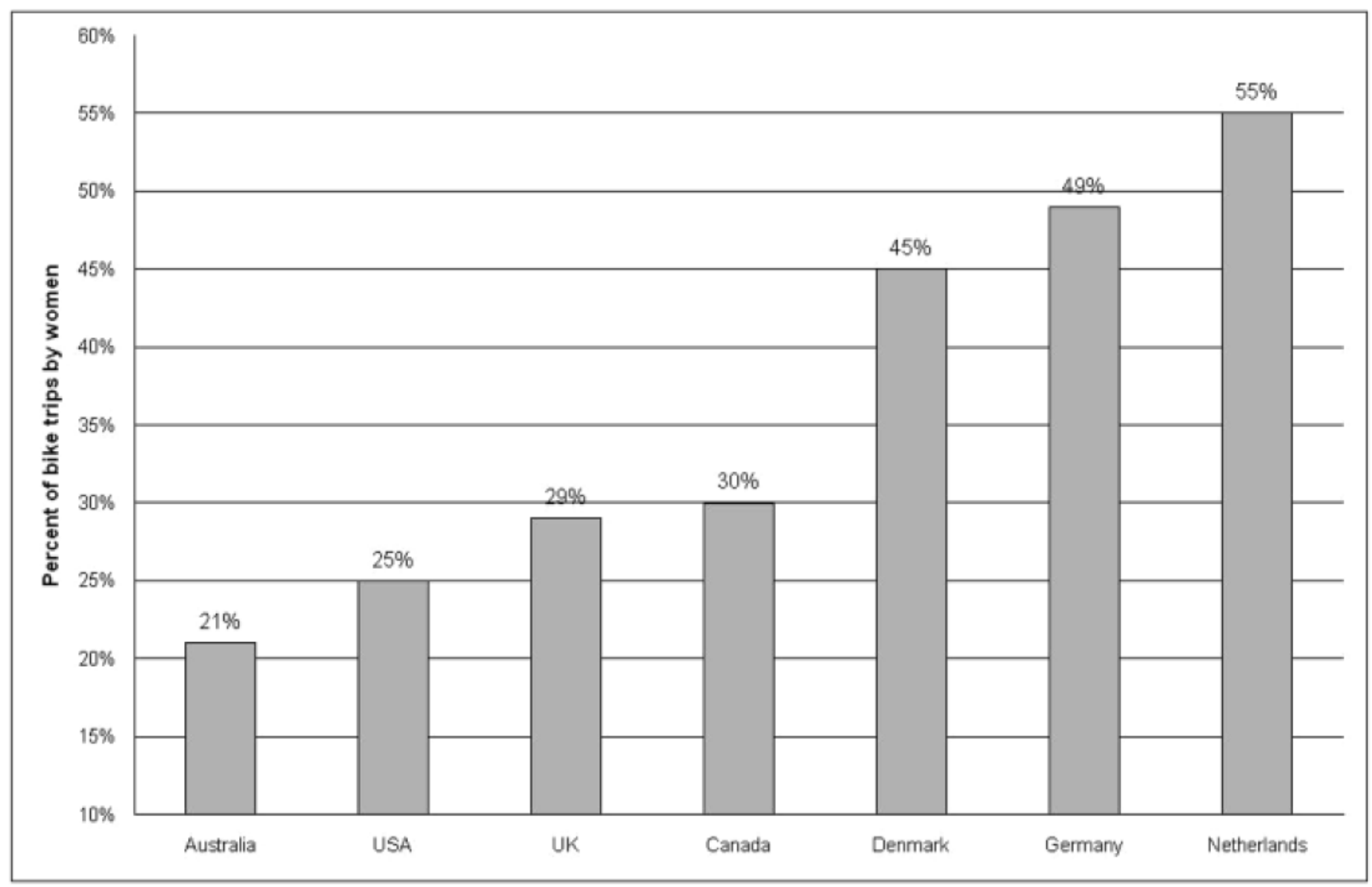

Sources: German Federal Ministry of Transport (2003); U.S. Department of Transportation (2003); Danish Ministry of Transport (2005); Statistics Netherlands (2005); Australian Bureau of Statistics (2007); Department for Transport (2007) and information provided directly by bike planners in Canadian provinces and cities 


\section{Gender gap in bicycling}
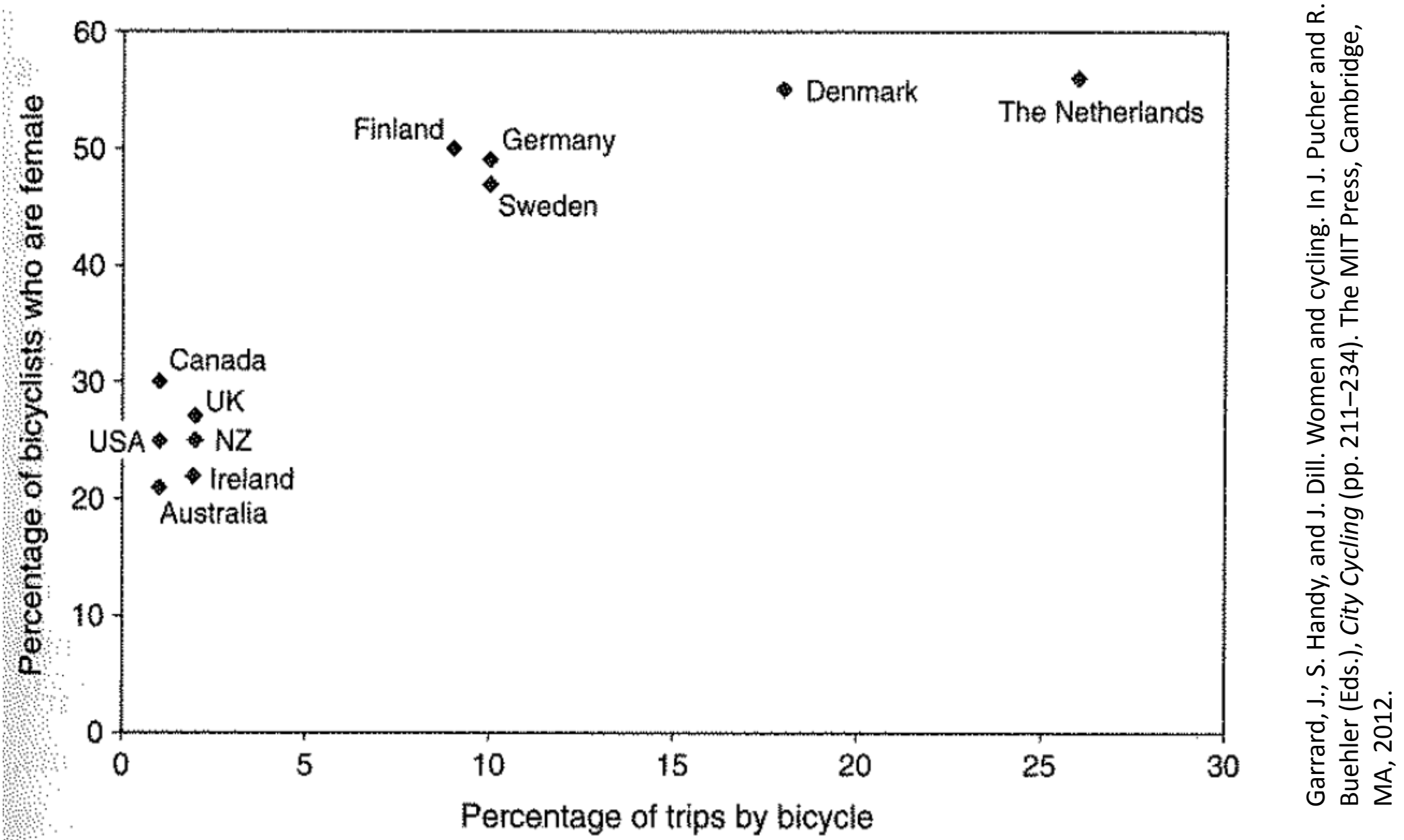

Gender gap in bicycling - Method \& data - Results - Discussion 


\section{Gender gap in bicycling 堨 Portland State}

- Goal: to understand bicycling's gender gap

- Importance of closing gender gap

- Health

- Well-being

- Access to jobs, services, and community

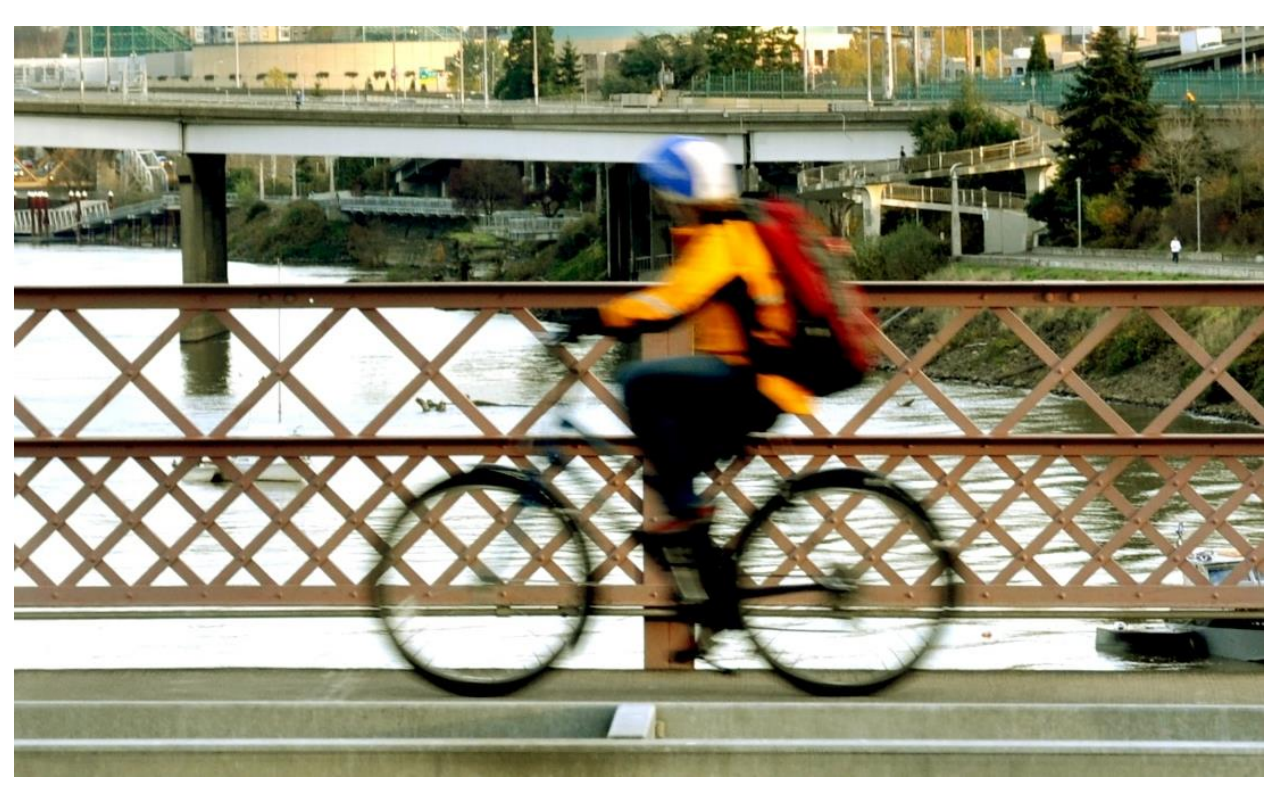

Gender gap in bicycling - Method \& data - Results - Discussion 


\section{Gender gap in bicycling 堨 Portland State}

- Explanations

- Bicycle facility preferences \& safety perceptions
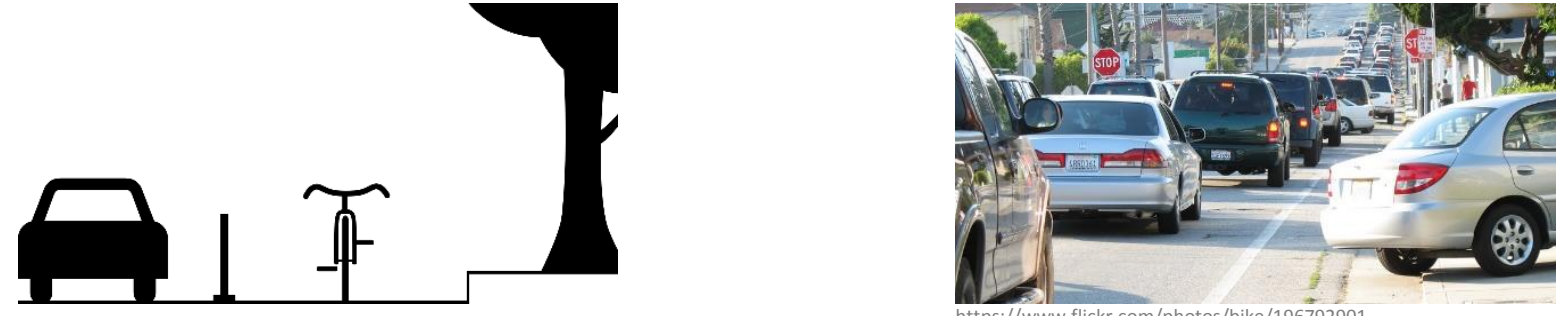

- Household responsibilities \& time constraints
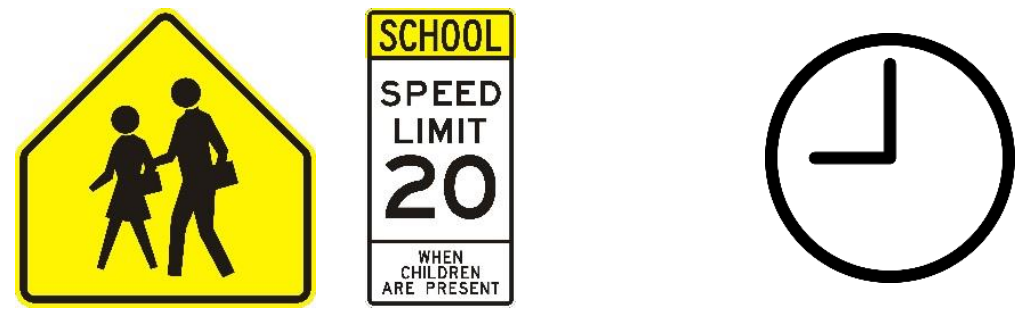

- Social normative gender roles

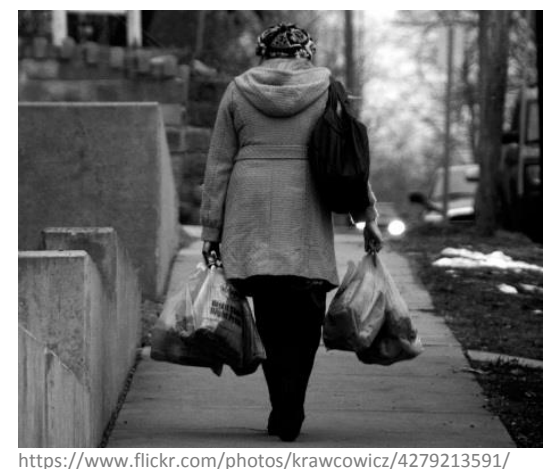




\section{Gender gap in bicycling}

- Our hypotheses

- Household maintenance responsibilities:

- Women with children $\rightarrow \downarrow$ bicycling

- Women with maintenance activities $\rightarrow \downarrow$ bicycling

- Single women $\rightarrow \uparrow$ bicycling

- Limited means and mobility options:

- Low-income women $\rightarrow \uparrow$ bicycling

- Women with $\downarrow$ vehicles $\rightarrow \uparrow$ bicycling 


\section{Method \& data}

- Method

- Travel behavior: cross-sectional, one-day

- Bicycle use by gender across demographic and household variables

- For any characteristic, looked for reduced or increased gender gap in bicycling

- Suggest possible interventions; or identify target populations for interventions 


\section{Method \& data}

- Data

- One-day, household-based, travel diary survey

- Weighted

$-30,090$ adults (age 18+)

2009-2011 


\section{Method \& data}

- Bivariate analysis

- Pearson's chi-squared tests of independence, two-way contingency tables

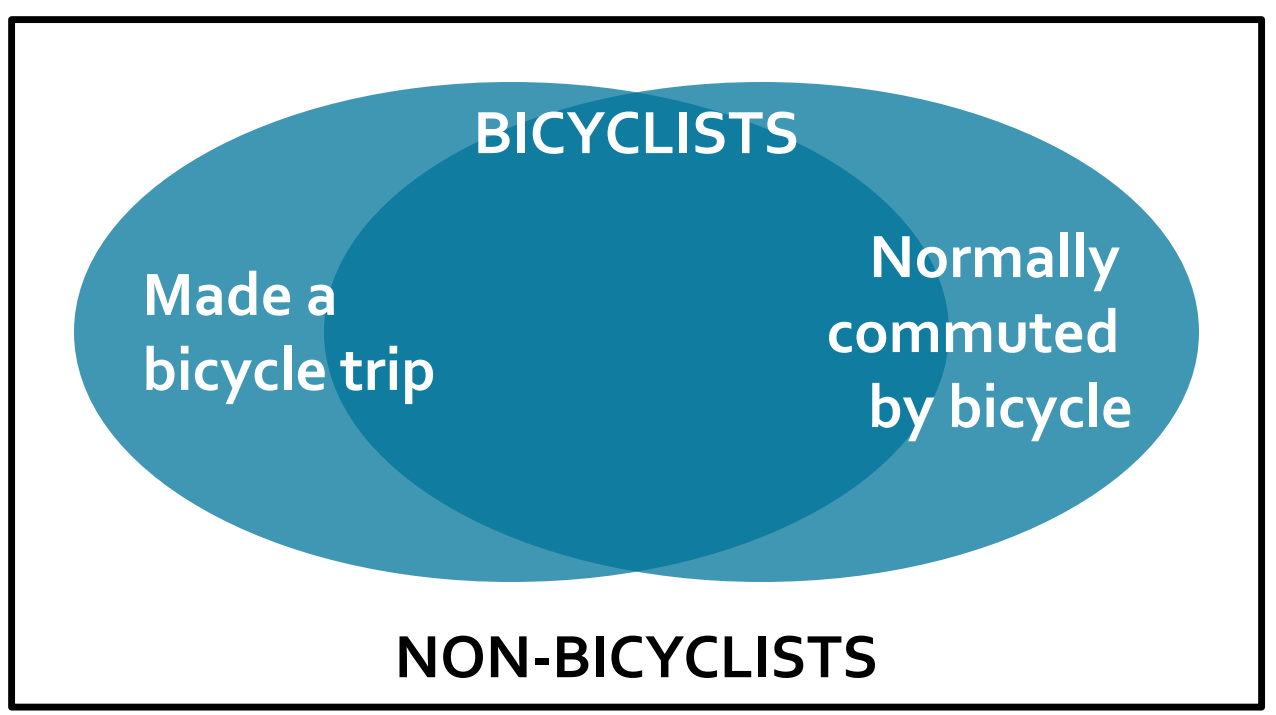

\begin{tabular}{lll}
\hline Bicycle use & Women & Men \\
\hline Made a bicycle & $2.8 \%$ & $5.5 \%$ \\
trip & $(453)$ & $(768)$ \\
Normally & $2.2 \%$ & $4.8 \%$ \\
commuted by & $(356)$ & $(665)$ \\
bicycle & & \\
\hline Bicyclists & $\mathbf{3 . 6 \%}$ & $\mathbf{7 . 4 \%}$ \\
& $(590)$ & $(1,023)$ \\
\hline
\end{tabular}

Gender gap in bicycling - Method \& data - Results - Discussion 


\section{Results}

\section{Percentage of bicyclists by gender for demographics}

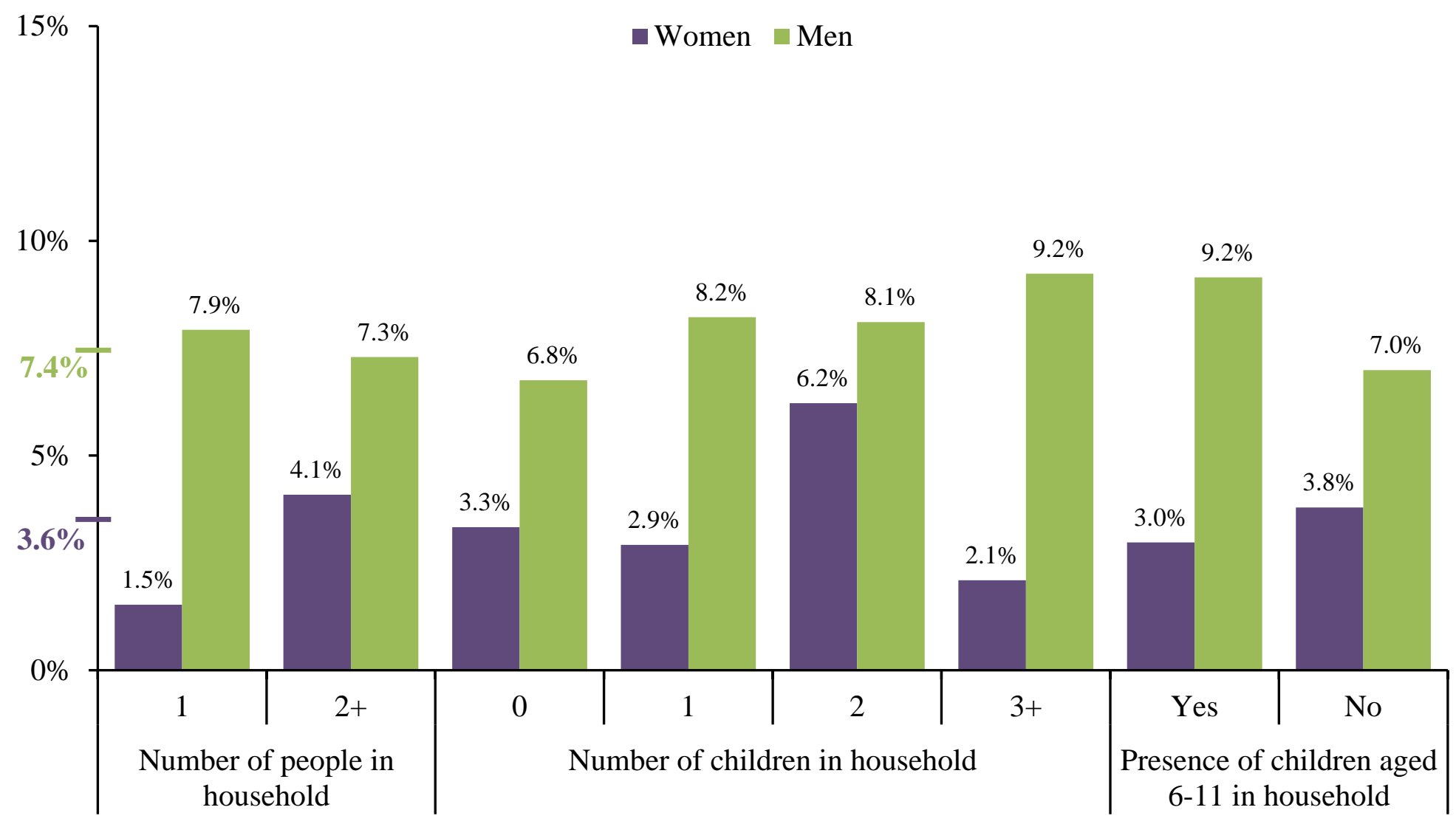




\section{Results}

\section{Percentage of bicyclists by gender for socioeconomics}

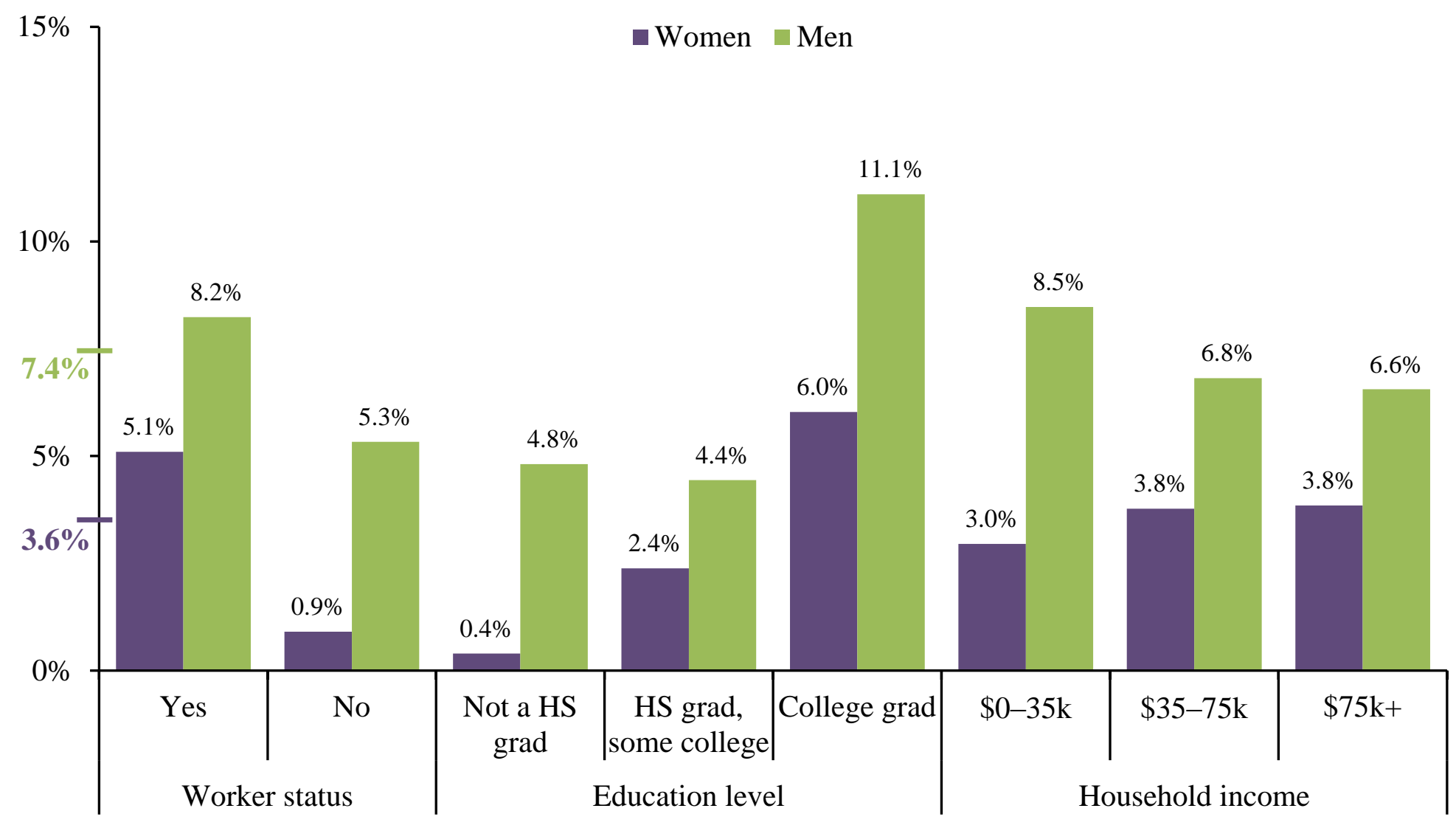

Gender gap in bicycling - Method \& data - 


\section{Results}

\section{Percentage of bicyclists by gender for mobility characteristics}

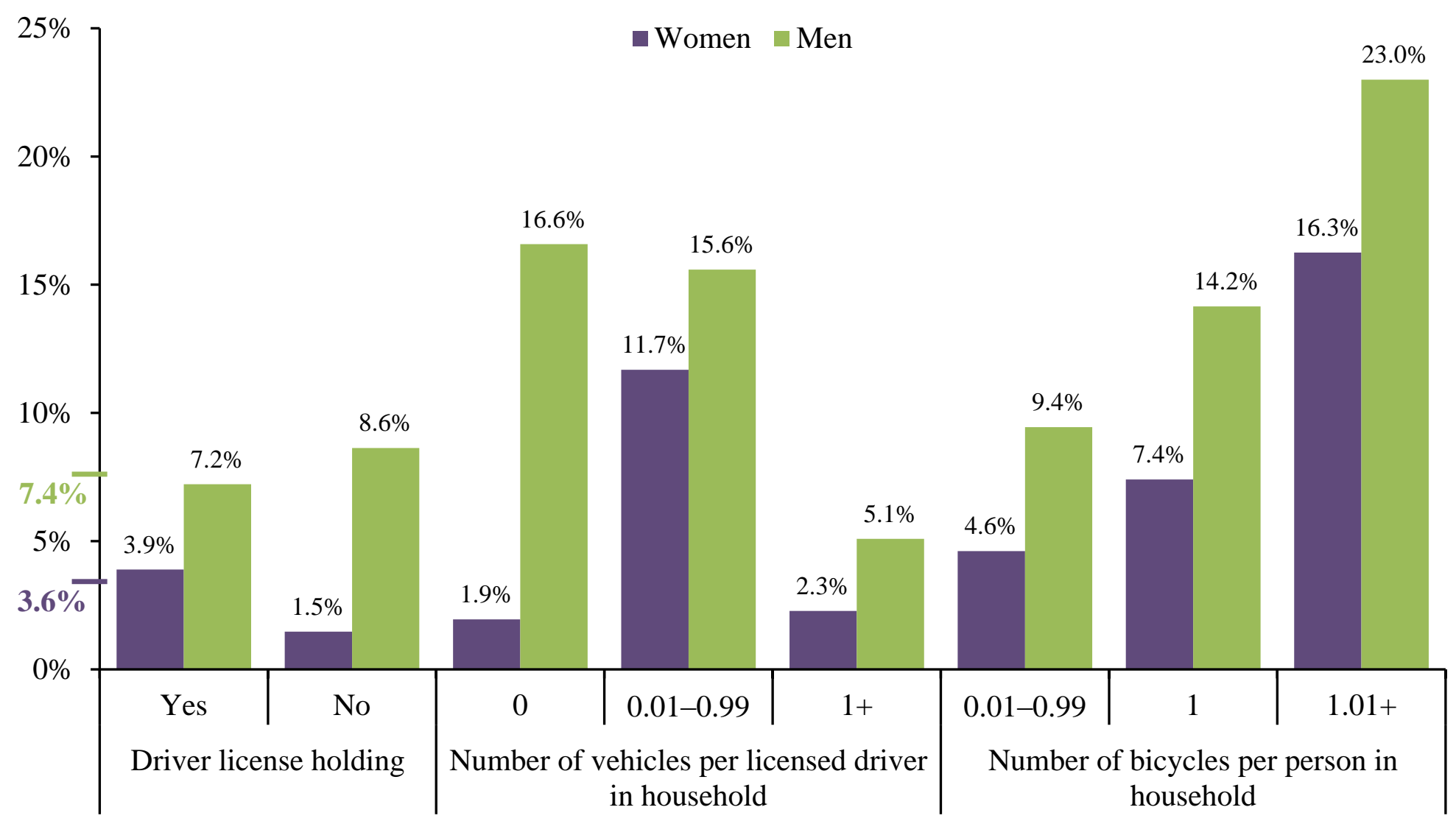

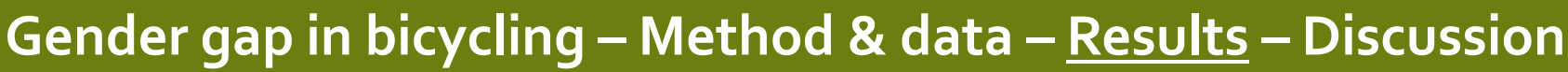




\section{Results}

\section{Percentage of bicyclists by gender for trip and activity characteristics}

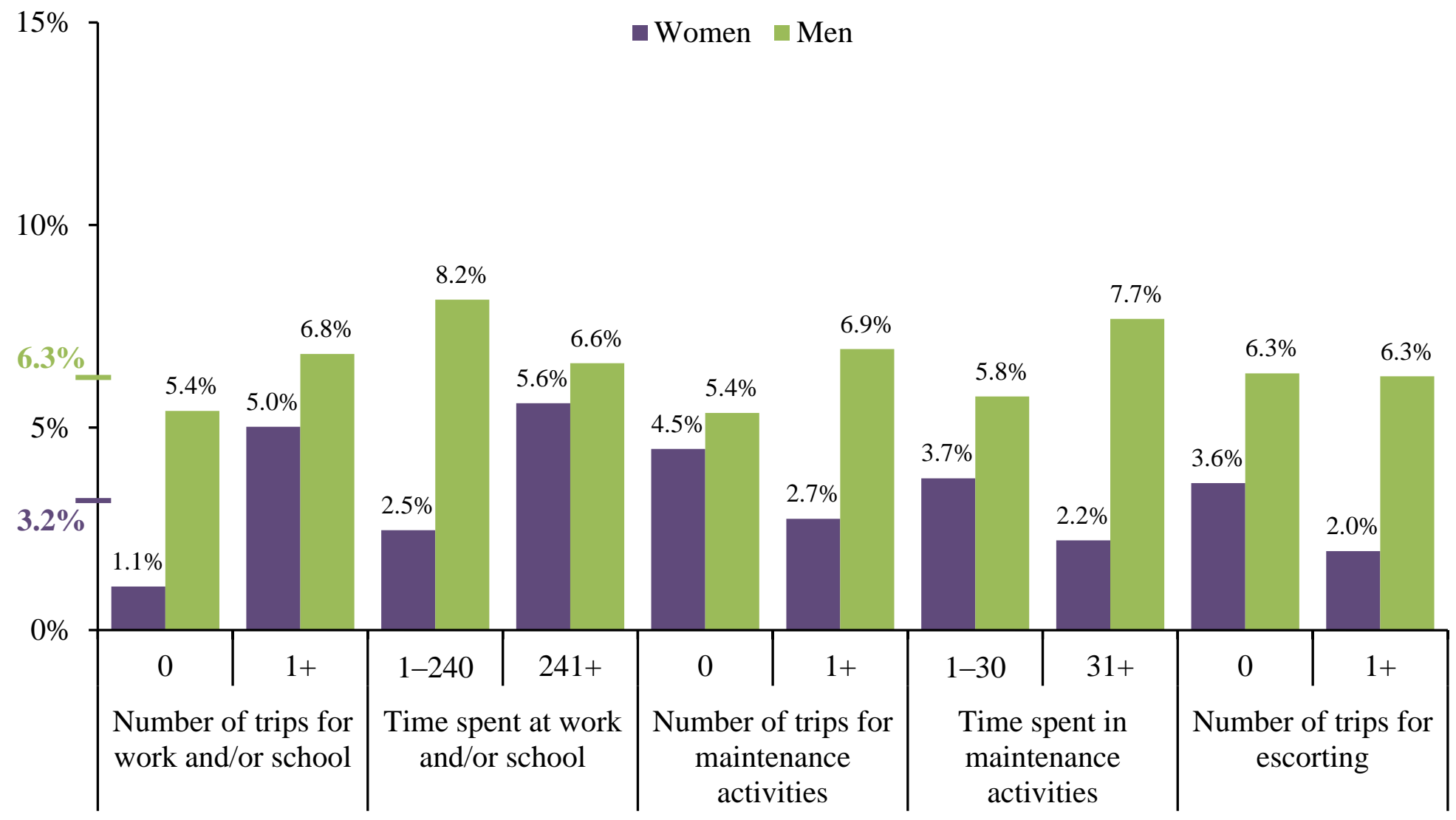




\section{Discussion}

- Women, household roles, and bicycling

- Household maintenance trip-making; time spent on maintenance activities:

- Women less likely to bicycle; men more likely.

- Women made more maintenance trips, and spent more time on maintenance activities.

- Presence of children:

- Women with 2+ children more likely to bicycle.

-Women with children aged 6-11 slightly less likely to bicycle; men more likely. 


\section{Discussion}

- Bicycling as a choice

- Women with more economic means and mobility options were more likely to bicycle:

- $\uparrow$ income, employed, Friday, driver license, motor vehicle access, $\uparrow$ bicycles.

- Bicycling (or not) by necessity

- Women with less economic means and limited mobility options were less likely to bicycle:

- < HS degree, not working, low-income HH, no work/school trips, no driver license, zero-vehicle $\mathrm{HH}$. 


\section{Discussion}

- Potential policy implications

- Target low-bicycling women:

- Living alone or in single adult $\mathrm{HH},<$ HS education, not working, no driver license, and/or living in lowincome or zero-vehicle $\mathrm{HH}$.

- Interventions:

- Infrastructure installations, awareness-raising, training, skills-building, and social events.
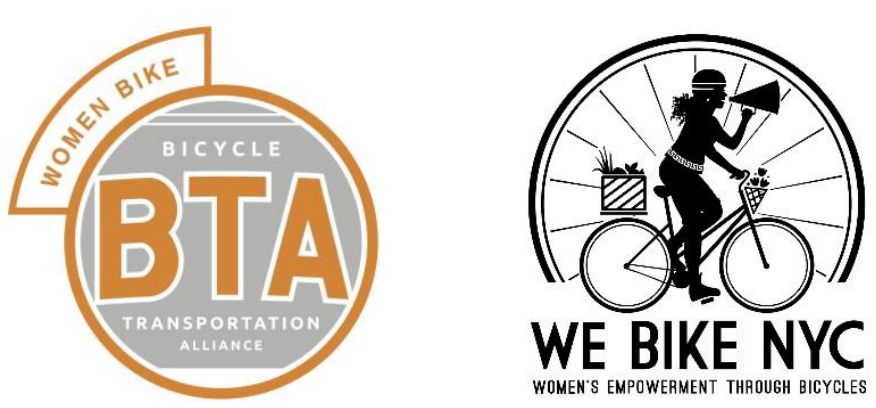


\section{Discussion}

- Future work

- Multivariate model of bicycling (gender $\times$ other variables)

- Multi-day travel survey, longitudinal data

- Data on built environment, bicycle facilities, safety, attitudes and preferences

- External validation of findings (beyond Oregon)

- Supplementary qualitative interviews, case studies, ..., to ask: Why? 


\section{Questions?}

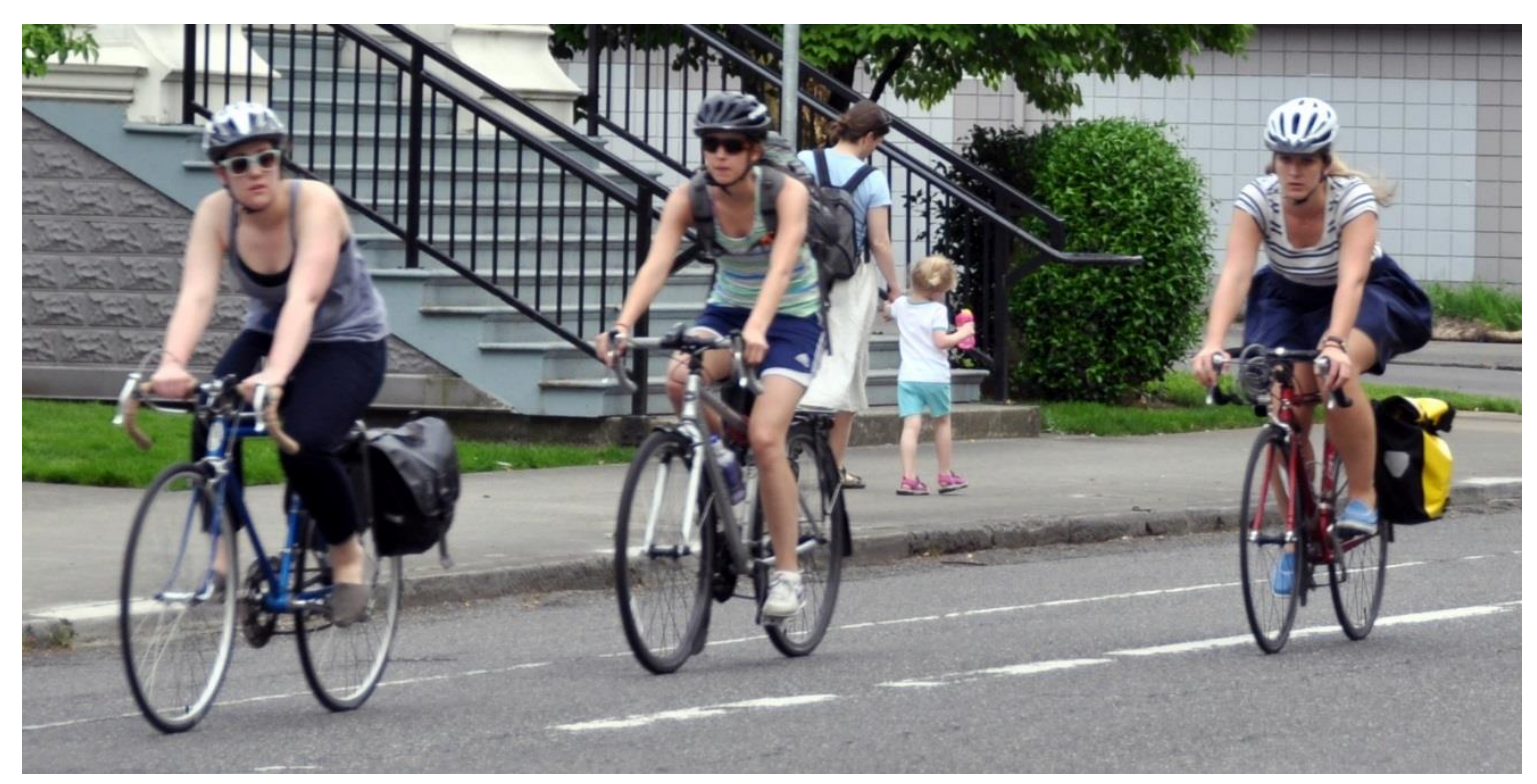

Patrick Singleton patrick.singleton@pdx.edu Tara Goddard goddard@pdx.edu

Gender gap in bicycling - Method \& data - Results - Discussion 